\title{
UMA ANÁLISE DOS PRODUTOS EDUCACIONAIS DA UTFPR QUE UTILIZAM TECNOLOGIAS DIGITAIS NO ENSINO DE MATEMÁTICA
}

\author{
Taniele Loss \\ tani_loss@hotmail.com \\ https://orcid.org/0000-0002-0384-3260 \\ UTFPR/Curitiba
}

Luciane Ferreira Mocrosky

mocrosky@utfpr.edu.br

https://orcid.org/0000-0002-8578-1496

UTFPR/Curitiba

\author{
Fabiana Roberta Gonçalves e Silva Hussein \\ fabianah@ufba.br \\ https://orcid.org/0000-0001-9961-7083 \\ UFBA/Bahia e PPGFCET da UTFPR/Curitiba \\ Marcelo Souza Motta \\ marcelomotta@utfpr.edu.br \\ https://orcid.org/0000-0001-5534-2735 \\ UTFPR/Curitiba
}

Recibido: 2020-04-09; Aceptado: 2020-11-17

\section{Resumo}

Este artigo aborda o uso de Tecnologias Digitais (TD) como recursos educacionais aos processos de ensino e de aprendizagem de Matemática, apresentados na forma de produtos educacionais desenvolvidos em Programas de Mestrados Profissionais da Universidade Tecnológica Federal do Paraná - UTFPR. O objetivo geral desta pesquisa é analisar e informar o que os produtos educacionais matemáticos, produzidos recentemente nestes Programas de Pós-graduação e direcionados ao Ensino Fundamental II e Médio mediante uso de TD, estão ofertando na área de Ensino de Matemática. Adotamos uma metodologia qualitativa por meio de uma investigação bibliográfica, mediante mapeamento em dissertações e produtos educacionais publicados entre os anos de 2017 a 2019. Observamos apenas três programas que se adequavam ao Ensino de Matemática e TD na UTFPR. Desses, elencamos doze produções que estavam de acordo com nosso objeto de estudo. Mediante leitura e análise dos dados, percebemos que os produtos educacionais que estão sendo ofertados atualmente condizem a sequências didáticas, cursos e guias sobre programação, construção e uso de jogos digitais e de Objetos de Aprendizagem por meio de softwares educacionais. Tais produtos são direcionados e ofertados ao ambiente educacional como meios metodológicos diferenciados aos processos de ensino e de aprendizagem de Matemática.

Palavras-chave: Produto Educacional. Ensino de Matemática. Tecnologias Digitais. 


\title{
UN ANÁLISIS DE PROYECTOS EDUCATIVOS DE LA UTFPR QUE USAN TECNOLOGIAS DIGITALES EN LA ENSEÑ̃ANZA DE MATEMÁTICAS
}

\begin{abstract}
Resumen
Este artículo aborda el uso de las Tecnologías Digitales (TD) como recursos educativos para los procesos de enseñanza y aprendizaje de matemáticas, presentados en forma de proyectos educativos desarrollados en los Programas de Maestría Profesional de la Universidad Tecnológica Federal de Paraná - UTFPR. El objetivo general de esta investigación es analizar e informar qué proyectos educativos matemáticos, producidos recientemente en estos Programas de Posgrado y dirigidos a los últimos años de la Escuela Primaria y Secundaria a través del uso de TD, están ofreciendo en el área de Enseñanza de Matemáticas. Adoptamos una metodología cualitativa a través de una investigación bibliográfica en tesis y proyectos educativos publicados entre 2017 y 2019. Observamos sólo tres programas que se ajustan a la Enseñanza de Matemáticas y TD en UTFPR. De ellos, enumeramos ocho producciones que estaban de acuerdo con nuestro objeto de estudio. A través de la lectura y el análisis de los datos, nos dimos cuenta de que los proyectos educativos que se ofrecen actualmente son consistentes con secuencias didácticas, cursos y guías sobre programación, construcción y uso de juegos digitales y objetos de aprendizaje a través de software educativo. Estos proyectos se dirigen y se ofrecen al entorno educativo como diferentes medios metodológicos para los procesos de enseñanza y aprendizaje de las matemáticas.
\end{abstract}

Palabras clave: Proyecto educativo. Enseñanza de matemáticas. Tecnologías Digitales.

\section{AN ANALYSIS IN EDUCATIONAL PRODUCTS FROM UTFPR USING DIGITAL TECHNOLOGIES IN MATHEMATICS TEACHING}

\begin{abstract}
This article discusses the use of Digital Technologies (DT) as educational resources to the teaching and learning processes in Mathematics, presented in the form of educational products developed in Professional Master's Programs of the Federal Technological University of Paraná - UTFPR. The main goal of this research is to analyze and inform what the mathematical educational products - recently produced in these Graduate Programs and directed to Primary and Secondary Education through the use of DT - are offering in the Mathematics Teaching area. We adopted a qualitative methodology through a bibliographic investigation, mapping dissertations and educational products published between the years 2017 to 2019 . We observed only three programs that were suitable for Mathematics Teaching and DT at UTFPR. From this observation, we list twelve productions that were in accordance with our object of study. After reading and analyzing the data, we realized that the educational products currently being offered are mainly didactic sequences, courses and guides on programming, construction and use of digital games and Learning Objects through educational software. Such products are directed and offered to the educational environment as differentiated methodological means to the teaching and learning processes in Mathematics.
\end{abstract}

Keywords: Educational Product. Mathematics Teaching. Digital Technologies.

\section{Introdução}


Atualmente, os Programas de Pós-Graduação de Mestrado Profissional na Área de Ensino (Área 46) visam a produção de pesquisas e produtos educacionais que contribuam de forma significativa aos processos educacionais da Educação Básica e do Ensino Superior. De acordo com o Documento de Área (Brasil, 2019, p. 9), cabe a tais programas "pensar e desenvolver ações que contribuam para reduzir a defasagem entre a pesquisa realizada na pósgraduação e o ensino realizado no contexto educacional, principalmente, da Educação Básica”, vindo a promover mudanças em tais contextos.

Nessa direção, esse mesmo documento aponta que os produtos educacionais devem ser criados para serem usados por professores e demais profissionais da Educação Básica e do Ensino Superior envolvidos com o ensino em espaços formais e não-formais. Nesse viés, Motta, Kalinke e Curci (2019, p. 239) afirmam que "é essencial o desenvolvimento de produtos educacionais que apresentem ações significativas para a prática cotidiana do professor de forma direta e simples". Com esse olhar, compreendemos que tais produtos devam ser criados e compartilhados na área de Ensino, a fim de divulgar materiais didáticos e metodologias que contribuam com os processos de ensino e de aprendizagem. Nesse movimento, uma das possibilidades dessas ações está no uso de Tecnologias Digitais (TD) ao Ensino de Matemática.

Este artigo tem como objetivo principal analisar e informar o que os produtos educacionais produzidos recentemente, entre 2017 e 2019, nos Programas de Mestrado Profissional da Universidade Tecnológica Federal do Paraná (UTFPR), direcionados ao Ensino Fundamental II e Ensino Médio mediante uso de TD, estão ofertando na área de Ensino de Matemática. Durante a investigação, observaremos os formatos desses produtos, o que propõem, direcionados para quais processos educacionais, se adotam alguma teoria de aprendizagem, e de que forma podem ser acessados, dentre outras observações.

Para isso, buscamos inicialmente em documentos técnicos da Coordenação de Aperfeiçoamento de Pessoal de Nível Superior (CAPES) informações sobre classificações dos produtos educacionais. Em seguida, apresentamos estudos sobre TD nos processos educacionais de Matemática. Na parte metodológica, realizamos uma investigação bibliográfica, mediante mapeamento em produtos educacionais e suas respectivas dissertações nos Programas de PósGraduação de Mestrado Profissional da UTFPR, que tratam do Ensino de Matemática por meio do uso de TD. Após análise desses produtos e suas dissertações, finalizamos com nossas considerações. 


\section{Classificação de produtos educacionais conforme a CAPES}

A CAPES é a fundação do Ministério da Educação (MEC) responsável pelo incentivo e expansão dos Programas de Pós-Graduação no âmbito federal. Á respeito dos produtos educacionais desenvolvidos nos Mestrados Profissionais, o Documento de Área 46 (Brasil, 2019, p.15) expressa que "o mestrando necessita desenvolver um processo ou produto educativo e aplicado em condições reais de sala de aula ou outros espaços de ensino, em formato artesanal ou em protótipo". Já para o Doutorado Profissional, esse mesmo documento frisa a importância de que os produtos sejam pensados "de modo que possa ser usufruída por professores da Educação Básica e do Ensino Superior, e por outros profissionais envolvidos com o ensino em espaços formais e não formais" (Brasil, 2019, p.15).

Constata-se que tal documento enfatiza que a modalidade profissional ${ }^{1}$ desenvolva materiais educacionais digitais ou não, que sejam direcionados e aplicáveis ao contexto da Educação Básica. Tal ação possibilita o repensar dos processos de ensino e de aprendizagem, podendo modificar e promover melhorias na área do Ensino.

Essas melhorias são como pontes entre os conhecimentos acadêmicos construídos nas pesquisas, para aplicações em produtos e processos educacionais direcionados à demanda social e às necessidades locais, regionais e nacionais. Portanto, a pesquisa em Ensino e seu respectivo produto educacional, tornam-se estratégicos para promover mudanças na Educação Básica e no Ensino Superior, vindo a contribuir para o impacto social e a proposição de políticas públicas relevantes e necessárias.

Nesta perspectiva, os Programas de Pós-Graduação se alinham para um planejamento estratégico, “considerando também articulações com o planejamento estratégico da instituição, com vistas à gestão do seu desenvolvimento futuro, adequação e melhorias da infraestrutura e melhor formação de seus alunos, vinculada à produção intelectual - bibliográfica, técnica e/ou artística" (Brasil, 2019, p. 8). Isso implica que os Programas elaborem seus planejamentos estratégicos a cada quatro anos (quadriênio), segundo os resultados do quadriênio anterior. Para tanto, é fundamental que considerem olhares para: a qualidade da formação dos pós-graduandos; os impactos sociais das ações do Programa; as ações de internacionalização; as inovações nas produções e nos processos acadêmicos (Brasil, 2019). Pois a cada quatro anos, a CAPES realiza

\footnotetext{
${ }^{1}$ Conforme a CAPES (2019), modalidade profissional condiz ao Mestrado e Doutorado Profissional.
} 
uma avaliação referente ao padrão acadêmico dos programas na modalidade profissional. Os resultados obtidos servem de parâmetro para formular políticas públicas destinados à área e concessão de bolsas de estudos. Dentre os aspectos avaliados, destacam-se os produtos educacionais.

De acordo com o Relatório de Avaliação Quadrienal CAPES (Brasil, 2017, p. 47), os produtos devem ser elaborados e "associados às dissertações dos mestrandos (trabalho de final de curso) e/ou [...] em autoria com discentes mestrandos", sendo elencados conforme as categorias:

- Protótipos educacionais e materiais para atividades experimentais, propostas de ensino, materiais textuais e interativos, mídias educacionais, desenvolvimento de aplicativos e atividades de extensão como cursos e oficinas;

- Editoria, tradução de obras, patentes, posfácio, prefácio, editorial, organização de eventos e artigos em revistas de divulgação científica;

- Apresentação de trabalho e outros produtos registrados;

- Serviços técnicos.

Diante dessa variedade de tipologias de produtos, como materiais interativos, propostas de ensino e tradução de obras, entende-se que a produção desses materiais atende a públicos específicos, abrangendo processos de ensino em espaço formal e/ou não formal (Brasil, 2017).

Segundo o Documento de Área 46 (Brasil, 2019), o produto educacional é o resultado de um processo criativo produzido baseado em uma pesquisa, visando responder a uma pergunta ou a um problema, ou então, a uma necessidade concreta relacionados ao campo de prática profissional, vindo a ser um artefato virtual ou real, ou um processo.

Perante tais informações, a apresentação de especificações e descrições técnicas desses materiais, devem seguir padrões de registros e acessibilidade a fim de garantir seu compartilhamento. Logo, o Relatório de Avaliação Quadrienal CAPES (Brasil, 2017) destaca que os produtos precisam ser registrados em formato digital e disponibilizados nos sites ou repositórios das respectivas instituições. Além disso, devem ser vinculados a um sistema de informações em âmbito nacional ou internacional, como por exemplo, ISBN ${ }^{2}$, ISSN ${ }^{3}$, Averbação

\footnotetext{
${ }^{2}$ O ISBN (International Standard Book Number), significa Número Padrão Internacional de Livros, identifica numericamente os livros segundo o seu título, autor, país, edição e editora.

${ }^{3}$ O ISSN (International Standard Serial Number), significa Número Internacional Normalizado para Publicações Seriadas, é utilizado para identificação de publicação em série, tendo aceite internacional.
} 
na Biblioteca Nacional, entre outros.

Notamos que o cumprimento dessas observações pode possibilitar o acesso de produtos educacionais por professores e profissionais envolvidos com o ensino de diferentes estados e regiões do país. Nesse movimento, pode ocorrer a promoção e uso de tais produtos, implicando em transformações nos processos de ensino e de aprendizagem.

\section{Tecnologias Digitais nos processos educacionais de Matemática}

Atualmente presenciamos um avanço tecnológico nos mais diversos contextos sociais. O uso de TD como computadores, smartphones e tablets são comuns entre os indivíduos da era digital. Estes as utilizam para as mais diversas situações, como se comunicar por meio das redes sociais, realizar uma investigação na web sobre estudos científicos e até mesmo organizar uma viagem de família. Nesta direção, Lévy (2010) aponta que o uso de TD pode modificar as formas do indivíduo pensar e de se comunicar, repercutindo em mudanças de comportamento social.

Visto que estudantes e professores fazem parte desse meio tecnológico, se faz necessário a utilização de TD dentro dos espaços escolares. Kenski (2012) defende que o uso de TD no contexto educacional, pode promover mudanças na forma de ensinar e de aprender, implicando em mudanças de ações e parcerias dos envolvidos. A pesquisadora ainda assume, que cabe ao professor se inteirar da tecnologia a ser utilizada, a direcionando para fins pedagógicos.

Algumas pesquisas e estudos acerca de cursos de formação de professores para o uso de TD ao ensino de Matemática (Diniz, 2015; Richit, Mocrosky \& Kalinke, 2015; Rocha, 2018; Elias, Motta \& Kalinke, 2018), indicam formas diferentes de (re)pensar o processo de ensino durante a formação inicial do professor, assim como na formação continuada. O uso de TD durante a formação inicial "pode além de preparar o professor para a inserção pedagógica destes recursos em sala de aula, despertar o gosto pela utilização destes meios digitais, tão presentes no contexto social" (Elias, Motta \& Kalinke, 2018, p. 425). Além disso, as TD devem ser “incorporadas às demais atividades formativas dos estudantes e professores, pois não faz sentido pensar que a educação tecnológica possa ser desenvolvida desvinculada da formação intelectual, acadêmica, cultural ou profissional” (Richit, Mocrosky \& Kalinke, 2015, p. 133).

Nesse enfoque, entendemos que as TD estão disponíveis ao meio educacional sendo importante a oferta de cursos para licenciandos e professores, a fim de promover reflexões sobre o uso delas nos processos educacionais, possibilitando práticas pedagógicas diferenciadas da 
tradicional.

Direcionando olhares às formas de aprender conteúdos matemáticos mediante o uso de TD, alguns estudos (Elias, Hussein \& Motta, 2018; Balbino, Nesi \& Kalinke, 2018; Nesi et al., 2018) revelam que o uso de smartphones e softwares educacionais pode propiciar formas diferentes do estudante ressignificar e construir conhecimentos. Essas constatações, muitas vezes estão relacionadas com os aspectos de interação e interatividade ${ }^{4}$ durante tais ações.

A respeito do uso pedagógico de smartphones, os estudantes podem elaborar "programas e aplicativos úteis para o cotidiano de forma a resolver desafios de ordem social, articulando conteúdos e disciplinas curriculares" (Elias, Hussein \& Motta, 2018, p. 17), promovendo momentos de produção de conhecimentos. Apoiando-nos na criação de jogos digitais e projetos por meio de softwares pedagógicos, o estudante pode passar de sujeito transformador a ativo do conhecimento. Tais evidências apontam para que haja uma continuidade de metodologias com o uso da linguagem de programação na elaboração, construção e apresentação de projetos realizados de forma cooperativa entre estudantes e professores (Balbino, Nesi \& Kalinke, 2018).

Diante dos expostos, percebemos que o estudante está inserido socialmente no meio digital, logo, cabe aos professores a busca pela oferta de TD ao contexto educacional, promovendo metodologias pedagógicas diferentes das tradicionais. Esse movimento oportuniza aos envolvidos uma imersão para investigar, supor, testar e construir conhecimentos matemáticos, resultando em formas diferentes de ensinar e de aprender a Matemática. Portanto, é importante que haja uma parceria entre professores e estudantes pela busca de novas metodologias que envolvam o uso de TD para fins pedagógicos. Desta forma, os mesmos se tornam agentes ativos nos processos educacionais, repercutindo mudanças de comportamento pela busca do saber.

\section{Metodologia}

Adotamos neste trabalho uma metodologia qualitativa por meio de uma investigação bibliográfica, mediante mapeamento de pesquisas. Segundo Fiorentini et al. (2016, p. 18), o mapeamento da pesquisa é "um processo sistemático de levantamento e descrição de

\footnotetext{
${ }^{4}$ Os autores supramencionados, adotam as definições de interação e interatividade apresentadas em Belloni (1999), em que a interatividade é compreendida como uma "característica técnica que significa a possibilidade de o usuário interagir com a máquina [...] e a interação consiste em uma ação recíproca entre dois ou mais atores onde ocorre a intersubjetividade" (Belloni, 1999, p. 58).
} 
informações acerca das pesquisas produzidas sobre um campo específico de estudo, abrangendo um determinado espaço (lugar) e período de tempo".

Com essa concepção, realizamos um levantamento bibliográfico de produtos educacionais, e suas respectivas dissertações, publicados entre os anos de 2017 a 2019 nos Programas de Mestrado Profissional da UTFPR. Consideramos os trabalhos direcionados ao Ensino de Matemática com o uso de Tecnologias Digitais para o Ensino Fundamental II e Médio, pois é a temática de pesquisa da maioria dos autores deste artigo.

Visando um olhar igualitário, consideramos os trabalhos desenvolvidos nesse período pois o Programa de Pós-Graduação em Ensino de Matemática (PPGMAT), de Cornélio Procópio e Londrina, iniciou suas publicações a partir do ano 2017. Desta forma, limitamos as investigações nesse intervalo de tempo.

Buscando atingir nosso objetivo principal, acessamos o site institucional da $\mathrm{UTFPR}^{5} \mathrm{e}$ verificamos quais eram os Programas de Mestrado Profissional direcionados ao Ensino de Ciências e Matemática mediante uso de Tecnologias. Dentre os 59 programas ofertados pela instituição, três se relacionavam com nossa investigação: Programa de Pós-Graduação em Ensino de Ciência e Tecnologia (PPGECT ${ }^{6}$ ) de Ponta Grossa; Programa de Pós-Graduação em Formação Científica, Educacional e Tecnológica (PPGFCET ${ }^{7}$ ) de Curitiba; e Programa de PósGraduação em Ensino de Matemática $\left(\mathrm{PPGMAT}^{8}\right.$ ) de Cornélio Procópio e Londrina.

A respeito de tais programas, o PPGECT oferta os cursos de mestrado e doutorado. $\mathrm{O}$ mestrado foi aprovado junto à CAPES no ano de 2007 e o doutorado em 2013. O programa busca formar profissionais voltados as áreas da Ciência, da Tecnologia e ao contex to do Ensino. O PPGFCET dispõe os cursos de mestrado e de doutorado, ambos aprovados pela CAPES. O mestrado iniciou suas atividades em 2011 e o doutorado em 2019. O programa visa promover a formação de professores e profissionais na área de Ensino de Ciências e Matemática, enunciando a alfabetização científica e tecnológica humanizadora. O PPGMAT tem o curso de mestrado aprovado desde 2015 pelo MEC. Tende a contribuir para a formação de profissionais para atuação no ensino de Matemática.

\footnotetext{
${ }^{5}$ Disponível em <http://portal.utfpr.edu.br/>. Acesso em 13 abr. 2020.

${ }^{6}$ Disponível em <http://portal.utfpr.edu.br/cursos/coordenacoes/stricto-sensu/ppgect/ppgmodelo>. Acesso em 02 abr. 2020.

${ }^{7}$ Disponível em <http://portal.utfpr.edu.br/cursos/coordenacoes/stricto-sensu/ppgfcet/home>. Acesso em 02 abr. 2020.

${ }^{8}$ Disponível em <http://portal.utfpr.edu.br/cursos/coordenacoes/stricto-sensu/ppg-mat>. Acesso em 02 abr. 2020.
} 
Cada programa selecionado direcionava a uma respectiva página informacional sobre o mesmo, disponibilizando o link de acesso aos respectivos sites. Ao acessá-los, havia uma aba intitulada Produção Acadêmica que direcionava ao Repositório Institucional da Universidade Tecnológica Federal do Paraná (RIUT ${ }^{9}$ ), exceto o PPGMAT que ofertava uma página somente com seus produtos educacionais e dissertações.

Investigando o PPGECT no RIUT, buscamos pelo assunto Ensino de Ciências e Matemática, data de publicação 2017, e encontramos 19 trabalhos. Destes, 17 eram dissertações e duas teses. Realizamos a leitura destes títulos e apenas um trabalho se adequava a nossa investigação. Repetimos tal processo para 2018, encontramos 12 trabalhos, sendo todos dissertações e nenhum abordava nosso tema de pesquisa. O mesmo ocorreu nos trabalhos de 2019, foram elencados oito, mas nenhum direcionado ao propósito desta pesquisa. Alertamos que os trabalhos não selecionados tratavam sobre o uso de TD ao Ensino de Ciências, Interdisciplinar, Educação Especial, Ensino Profissional e Ensino Superior. Portanto, não se adequavam a nossa sondagem e foram descartados.

Observando o PPGFCET no RIUT, selecionamos o assunto Ensino de Ciências e Matemática, ano 2017, e encontramos 14 trabalhos. Fazendo a leitura dos títulos, apenas um abordava o nosso tema de investigação. Repetimos tal processo para 2018, encontramos 19 trabalhos. Destes, três foram selecionados pois tratavam do assunto a ser investigado. Em 2019, até o momento desse levantamento de dados, foram apresentados cinco trabalhos, mas nenhum direcionado ao propósito desta pesquisa.

Em nossa investigação ao repositório do PPGFCET, frisamos que grande parte dos trabalhos encontrados abordavam estudos direcionados ao Ensino de Ciências. Tal percepção, deve-se a recente integração da área de Ensino de Matemática ao referido programa, a partir de 2018. Isto justifica o baixo número de pesquisas e produtos direcionados ao Ensino de Matemática mediante uso de TD.

A aba de Produção Acadêmica do PPGMAT apresentava duas opções: Quadro de Resumos de Produtos Educacionais publicados pelo programa desde 2017 a 2019 , e Relação das Dissertações defendidas no programa desde 2017 a 2019. Ao selecionar o Quadro de Resumos de Produtos Educacionais, encontramos 39 produtos educacionais. Realizamos a leitura desses resumos e identificamos sete produtos que estavam em consonância com a

\footnotetext{
${ }^{9}$ Disponível em <http://repositorio.utfpr.edu.br/jspui>. Acesso em 02 abr. 2020.
} 
temática desta pesquisa. Destacamos que os produtos desconsiderados nesta sondagem, conferiam estudos ao Ensino Superior, Profissional e Prisional, ou por não utilizarem TD. Diante disso, foram descartados de nossa análise.

No Quadro 1 a seguir, destacamos os trabalhos analisados e selecionados nos três programas investigados. O mesmo foi estruturado conforme o programa e cronologia de publicação dos respectivos autores.

Quadro 1 - Trabalhos analisados e selecionados nesta investigação

\begin{tabular}{|c|c|c|}
\hline Programa & Título da Dissertação (D) e do Produto Educacional (PE) & $\begin{array}{l}\text { Autor/ } \\
\text { Ano de } \\
\text { publicação }\end{array}$ \\
\hline PPGECT & $\begin{array}{l}\text { (D/PE) Tecnomatemática: site como ferramenta tecnológica para o } \\
\text { ensino de frações no } 6^{\circ} \text { ano do ensino fundamental }\end{array}$ & Cruz (2017) \\
\hline PPGFCET & $\begin{array}{l}\text { (D/PE) Uma proposta de estudo da autonomia docente de } \\
\text { professores de ciências e de matemática em exercício }\end{array}$ & $\begin{array}{l}\text { Maciel Junior } \\
\text { (2017) }\end{array}$ \\
\hline PPGFCET & $\begin{array}{l}\text { (D/PE) Possibilidades de utilização de smartphones em sala de aula: } \\
\text { construindo aplicativos investigativos para o trabalho com equações } \\
\text { do } 2^{\circ} \text { grau }\end{array}$ & $\begin{array}{l}\text { Elias (2018a, } \\
2018 b)\end{array}$ \\
\hline PPGFCET & $\begin{array}{l}\text { (PE) Objeto de Aprendizagem "Descobrindo Comprimentos" versão } \\
2.0 \\
\text { (D) Reformulando um objeto de aprendizagem criado no Scratch: } \\
\text { em busca de melhorias na usabilidade }\end{array}$ & $\begin{array}{l}\text { Nesi }(2018 a, \\
2018 b)\end{array}$ \\
\hline PPGFCET & $\begin{array}{l}\text { (PE) O Objeto de Aprendizagem - O skate e a Trigonometria } \\
\text { (D) Objetos de aprendizagem aplicados ao ensino da trigonometria: } \\
\text { revelando elementos a partir do movimento histórico e lógico }\end{array}$ & $\begin{array}{c}\text { Silva ((2018a, } \\
\text { 2018b) }\end{array}$ \\
\hline PPGMAT & $\begin{array}{l}\text { (PE) Contribuiçães ao Ensino de Geometria por meio da criação de Objetos de } \\
\text { Aprendizagem } \\
\text { (D) O software de programação Scratch na formação inicial do } \\
\text { professor de matemática por meio da criação de objetos de } \\
\text { aprendizagem }\end{array}$ & $\begin{array}{l}\text { Curci }(2017 a \text {, } \\
\text { 2017b) }\end{array}$ \\
\hline PPGMAT & $\begin{array}{l}\text { (PE) Afinal, como surgiram as Geometrias não euclidianas? } \\
\text { (D) Vídeos didáticos e atividades baseadas na história da } \\
\text { matemática: uma proposta para explorar as geometrias não } \\
\text { Euclidianas na formação docente }\end{array}$ & $\begin{array}{c}\text { Gomes(2017a, } \\
2017 b)\end{array}$ \\
\hline PPGMAT & $\begin{array}{l}\text { (PE) Desmistificando a Matemática por meio da Estatística } \\
\text { (D) Uma aplicação de vlogs nas aulas de estatística na educação } \\
\text { básica }\end{array}$ & $\begin{array}{l}\text { Morais }(2017 \mathrm{a}, \\
2017 \mathrm{~b})\end{array}$ \\
\hline PPGMAT & (PE/D) Um estudo sobre o ensino de geometria com o uso da FARMA & $\begin{array}{l}\text { Pereira }(2018 \mathrm{a}, \\
2018 \mathrm{~b})\end{array}$ \\
\hline PPGMAT & $\begin{array}{l}\text { (D) Ensino de Estatística: o estudo de conceitos potencializado pelo } \\
\text { software RStudio } \\
\text { (PE) Mapas e contornos: caminhos para o ensino de Estatística no } \\
\text { RStudio }\end{array}$ & $\begin{array}{l}\text { Cardoso (2019a, } \\
\text { 2019b) }\end{array}$ \\
\hline PPGMAT & (PE) Atividades para ensinar multiplicação e divisão de polinômios & $\begin{array}{c}\text { Coutinho } \\
(2019 \mathrm{a}, 2019 \mathrm{~b})\end{array}$ \\
\hline
\end{tabular}




\begin{tabular}{|l|l|c|}
\hline & $\begin{array}{l}\text { (D) Divisão e multiplicação de polinômios com o auxílio de } \\
\text { materiais manipuláveis e tecnologias sob o olhar da representação } \\
\text { semiótica }\end{array}$ & \\
\hline PPGMAT & $\begin{array}{l}\text { (D) A utilização do smartphone com intermédio de um aplicativo de } \\
\text { realidade aumentada para a aprendizagem de Estatística } \\
\text { (PE) Livro interativo de Realidade Aumentada para o Ensino de } \\
\text { Estatística }\end{array}$ & $\begin{array}{c}\text { Domingues } \\
\text { (2019a, 2019b) }\end{array}$ \\
\hline
\end{tabular}

Fonte: os autores (2020)

Após selecionados os doze trabalhos, realizamos os downloads dos referidos produtos educacionais e suas respectivas dissertações. Constatamos no RIUT que havia apenas os arquivos das dissertações de Cruz (2017) e Maciel Junior (2017), não sendo disponibilizadas postagens para os produtos, como os demais. Por este fato, fizemos inicialmente uma leitura flutuante em ambas as dissertações e constatamos que os produtos estavam contidos no decorrer do corpo textual. Desta forma, ambos não foram descartados de nossa investigação.

Após downloads, iniciamos a leitura dos resumos das dissertações e apresentações iniciais dos produtos educacionais. Diagnosticado que os doze trabalhos estavam coerentes com nosso objeto de estudo, realizamos a leitura integral dos produtos educacionais e suas respectivas dissertações. Na sequência, seguem as análises dos dados levantados.

\section{Compreensões dos produtos educacionais selecionados}

Neste momento, apresentamos nossas interpretações referentes aos trabalhos elencados no Quadro 1. Buscamos considerar nos produtos educacionais as seguintes características: formato; proposta educacional; processos educacionais; teoria de aprendizagem; e acesso. Além de trazer os pontos positivos e negativos desses ao uso escolar. Nas respectivas dissertações, procuramos examinar as linhas teóricas adotadas para o desenvolvimento dos produtos, registros da criação dos mesmos e informações que contribuíssem em nossa análise. Com esses preceitos passamos a observar os referidos trabalhos.

O produto educacional apresentado por Cruz (2017) ao PPGECT é o site educacional Tecnomatemática ${ }^{10}$. O mesmo foi desenvolvido pela pesquisadora com o intuito de auxiliar professores e estudantes no uso das Tecnologias da Informação e Comunicação (TIC), relacionadas à disciplina de Matemática. Para construí-lo, a pesquisadora buscou compreensões

${ }^{10}$ Conforme informações de Cruz (2017), atualmente o site <http://www.tecnomatematica.com> não está funcionando devido a questões técnicas. 
sobre o ensino e a aprendizagem da Matemática, restringindo olhares ao uso de TD. Desta forma, entre outros autores, baseou seus estudos em Vygotsky (1998), D’Ambrósio (2010), Freire (1996), Borba e Penteado (2007), Kenski, (2010) e Valente (1993).

Com o aporte teórico escolhido, desenvolveu-se e apresentou-se um site no decorrer do curso de formação continuada à professores de Matemática do Ensino Fundamental II, de uma escola estadual pública de Jacarezinho/PR, com o objetivo de analisar se o mesmo poderia ser uma ferramenta tecnológica para o ensino do conteúdo de frações ao $6^{\circ}$ ano. Durante tal curso, os professores participantes criaram atividades educacionais sobre frações com o uso do software JClic ${ }^{11}$, que foram incluídas pela pesquisadora no site, como materiais educacionais para downloads. Tal site traz em sua página inicial os ícones: Cursos, Notícias, Downloads, Imagens e Contato. A seguir, a Figura 1 apresenta tal página que está exposta na dissertação da respectiva pesquisadora pois o site está inativo.

Figura 1 - Interface inicial do Tecnomatemática

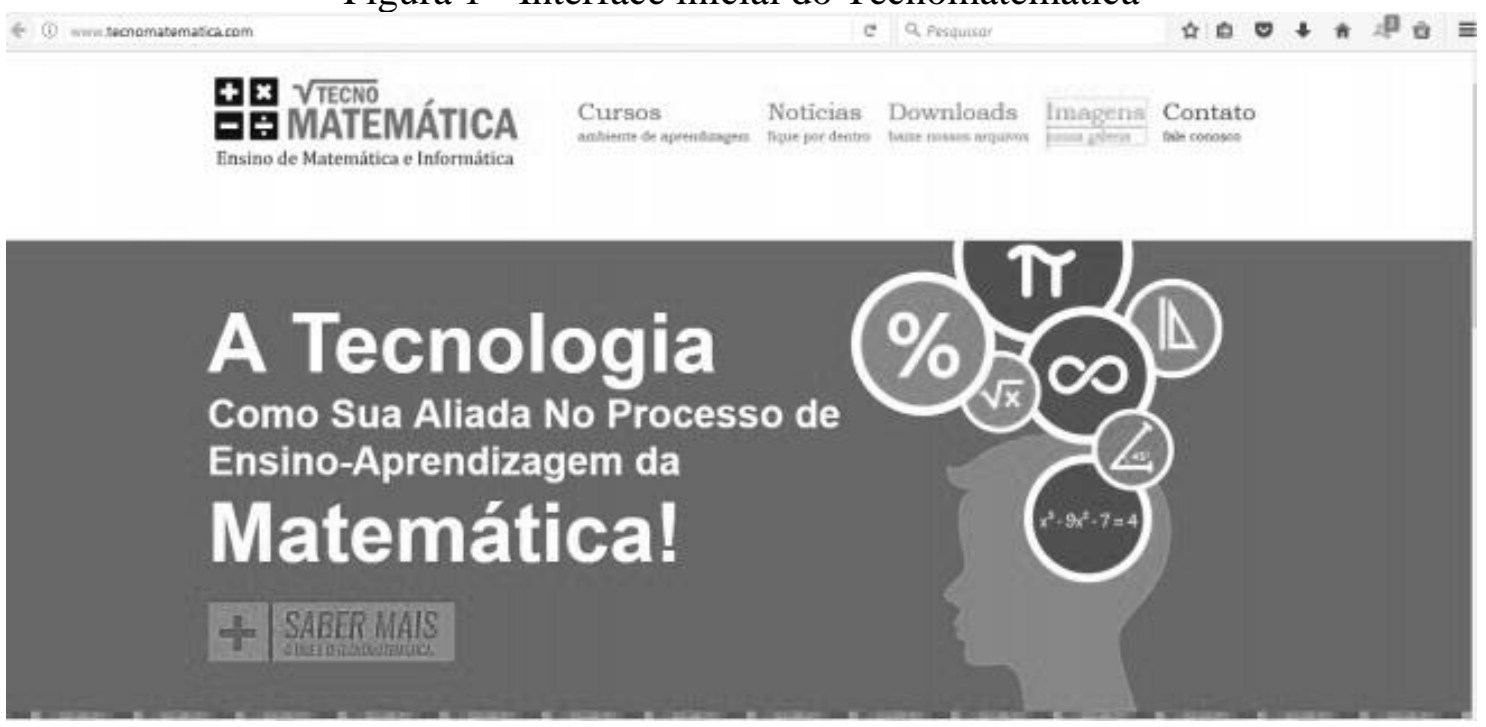

Fonte: Cruz (2017)

Cruz (2017) salientou que o ícone "Cursos", que disponibilizaria cursos na modalidade Educação a Distância $(\mathrm{EaD})$, não estaria ativado pois seria pertinente realizar nova pesquisa sobre EaD, além de desenvolver materiais específicos para tal finalidade. Em "Notícias" há informações de outras fontes relacionadas ao uso das TIC para o ensino da Matemática. O ícone "Downloads" apresenta links que direcionam a sites de softwares que podem ser utilizados de

\footnotetext{
${ }^{11}$ Disponível em: <https://clic.xtec.cat/legacy/en/jclic/>. Acesso em 02 abr. 2020.
} 
forma livre, como por exemplo, CmapTools, GeoGebra e JClic. Em "Imagens", há o direcionamento à página no Facebook ${ }^{12}$, contendo informes sobre o uso de TIC e Matemática, além de fotos da aplicação do curso de formação continuada com os professores, realizado durante sua pesquisa. Já em "Contato", o usuário pode enviar mensagem a desenvolvedora do site, tirando dúvidas e deixando sugestões.

Por fim, a pesquisadora concluiu que o site foi bem aceito pelos participantes do curso de formação pois concentra uma variedade de informações relacionadas ao uso das TIC na Matemática. Assim, o mesmo pode ser utilizado para auxiliar os professores no ensino de Matemática, possibilitando a contextualização de situações pertinentes à realidade do estudante (Freire, 1996), podendo implicar nos processos de aprendizagem (Vygotsky, 1998; D’Ambrósio, 2010).

Como não conseguimos acessar o site, pois o mesmo não está disponível devido a questões técnicas, observamos os materiais expostos e produzidos no decorrer do curso na página do grupo no Facebook. Nela, notamos que, além desses, a mesma é alimentada e atualizada com informações pertinentes quanto ao uso de TIC no ensino de Matemática. Consideramos que tais referências podem contribuir de forma positiva para as práticas pedagógicas pois conduzem ao uso de vídeos, softwares e outros recursos tecnológicos. Um ponto negativo é que o site não está em funcionamento, restringindo acesso ao seu material apenas pela rede social.

Acerca do produto educacional exposto ao PPGFCET por Maciel Junior (2017), o curso de robótica educacional ${ }^{13}$ foi construído e desenvolvido junto aos professores de Ciências, Matemática, Física, Química e Biologia da rede estadual pública de ensino do núcleo de Pato Branco/PR. O pesquisador buscou analisar neste curso a autonomia docente sob a perspectiva de Contreras (2012) e Habermas (2012). Tais autores defendem que o desenvolvimento das habilidades comunicativas do professor e de seu aprendiz são mais relevantes que a centralidade do processo de ensino/aprendizagem.

Referente ao produto educacional, o curso foi ofertado em 60 horas, distribuídas em 20 encontros. As atividades foram realizadas por duplas e trios, o que propiciou momentos de discussão sobre possíveis soluções para determinados problemas, precipitando espaços para

\footnotetext{
${ }^{12}$ Disponível em: <https://www.facebook.com/tecnomatematica〉. Acesso em 02 abr. 2020.

13 O curso está descrito a partir da página 72 da dissertação do pesquisador. Disponível em: <http://repositorio.utfpr.edu.br/jspui/handle/1/2884>. Acesso em 02 abr. 2020.
} 
autonomia do professor e racionalidade comunicativa, objeto de estudo do pesquisador. Nessas atividades, os participantes exploraram conteúdos de Ciências e Matemática no decorrer da montagem, programação e análise dos experimentos propostos para a criação de robôs. Algumas das atividades do curso, como o funcionamento do robô e o controle da placa por programação para o acionamento de uma lâmpada incandescente, puderam ser divulgados durante a mostra de cursos do Instituto Federal do Paraná (IFPR), campus Palmas. Tal evento possibilitou uma maior difusão regional do uso da robótica ao ensino da área de Ciências e Matemática pois contou com a visita de estudantes e professores da rede pública e privada da cidade e região.

Neste movimento, o pesquisador identificou que a metodologia de ensino aplicada no curso de robótica privilegiou a resolução de problemas práticos, contribuindo significativamente para o estudo, indo ao encontro das ideias de Contreras (2012) e Habermas (2012). Isto posto, os professores notaram que a autonomia para o ensino e a aprendizagem vai além de conteúdos disciplinares, possibilitando "uma visão humanista do ensino, atuando de forma mais crítica e reconhecendo o aspecto intersubjetivo dessa reflexão" (Maciel Junior, 2017, p.102). Tal produto está incluso na dissertação do respectivo pesquisador e pode ser acessado por meio do RIUT.

Um ponto positivo no tocante do curso, é a integração de conhecimentos de Ciências e Matemática por meio da robótica, o que pode implicar em ações interdisciplinares e promoções do uso pedagógico da programação no Ensino Fundamental II e Ensino Médio. Concebemos como ponto negativo, que o produto educacional é abordado no decorrer da dissertação, no capítulo da metodologia. Isto leva o leitor a acessar tal trabalho e buscar informações que sejam relevantes para ele. Tal ocasião se deve a não exigência do programa, na época, em haver dissertação e produto educacional separados, tornando-se obrigatória a partir de 2018.

O produto educacional de Elias (2018b), apresentado ao PPGFCET, consta de um material com quatro aplicativos matemáticos educativos criados no software App Inventor 2, para o ensino de Equações do $2^{\circ}$ grau. Os mesmos são acompanhados por quatro sequências didáticas, além dos processos de programação para criação de cada um deles.

Durante sua pesquisa, Elias (2018a) criou tais aplicativos e os apresentou aos estudantes de uma turma de $9^{\circ}$ ano do Ensino Fundamental II, de uma escola estadual pública de Curitiba/PR buscando indícios da ressignificação da aprendizagem sobre Equações do $2^{\circ}$ grau. A pesquisadora baseou seus estudos em Ausubel (1980) com a Aprendizagem Significativa, e 
em Papert (1986) com a teoria Construcionista e as dimensões basilares: pragmática, sintônica, sintática, semântica e social.

Quanto aos aplicativos: um corresponde a um Quiz ${ }^{14}$ a respeito da história da Álgebra e das Equações Quadráticas; outro condiz à seleção de opções corretas quanto a lei de formação de uma Equação Quadrática; outro oportuniza escolha de alternativas verdadeiras e falsas a respeito dos coeficientes de uma Equação do $2^{\circ}$ Grau e a função do discriminante; e por fim, o aplicativo em formato de calculadora em que o usuário indica os coeficientes de uma Equação do $2^{\circ}$ grau e ele calcula as raízes dessa equação.

Tais aplicativos estão disponíveis no site do App Inventor ${ }^{15}$, podendo o usuário acessálos mediante cadastro na plataforma. Após isso, poderá "baixar" o(s) aplicativo(s) em um smartphone, explorando-os de forma pedagógica. Também, o usuário poderá alterar a programação, remixando-o conforme suas necessidades pedagógicas, sendo, assim, um produto declaradamente aberto a possibilidades de ensino e de aprendizagem.

Elias (2018a) identificou as concepções teóricas da Aprendizagem Significativa (Ausubel, 1980), em que os estudantes, na assimilação de novos conhecimentos, lançavam mão de saberes prévios. Além disso, observou que o uso de smartphones contemplou as dimensões sintática, semântica e social (Papert, 1986), visto que os estudantes possuem rápido acesso e facilidade de manipulação a este material. A respeito dessas dimensões, a pesquisadora indica que a dimensão sintática considera que a realização de trabalhos contextualizados deve surgir a partir do interesse do estudante, oportunizando maior assimilação e aprendizado efetivo; a semântica expressa a importância do estudante explorar materiais que tenham significado para ele, possibilitando uma relação mais acessível ao aprendizado; e a dimensão social caracteriza que o trabalho com materiais culturalmente inseridos no cotidiano do estudante, é de grande relevância para o aprendizado.

Por fim, a pesquisadora constatou que o uso de smartphones no contexto educacional é um recurso que pode auxiliar no processo de aprendizado de Matemática, oportunizando formas diferentes para ressignificar aprendizagens de estudantes e promover o uso de tecnologias móveis em contexto escolar.

\footnotetext{
${ }^{14}$ Quiz é um jogo de perguntas que tem como objetivo avaliar os conhecimentos dos jogadores (Elias, 2018).

${ }^{15}$ Disponível em <http://appinventor.mit.edu/explore>. Acesso em 02 abr. 2020.
} 
Observando tal produto educacional, destacamos positivamente a versatilidade dos aplicativos em ofertarem conteúdo matemático específico por meio de quiz ao uso de calculadora, possibilitando a mobilidade e o uso pedagógico de smartphones e tablets. Ressaltamos como pontos negativos o acesso e a velocidade da internet da escola ou da rede de dados privada do aluno e/ou do professor; além da posse de smartphones, pois nem todos os estudantes possuem ou portam para a escola tais aparelhos.

Nesi (2018a) apresentou como produto educacional ao PPGFCET, o OA "Descobrindo Comprimentos - versão 2.0"16. Este objeto corresponde a um recurso virtual multimídia, criado no software Scratch, que oferta um jogo digital sobre o conteúdo matemático de Unidades de Medidas de Comprimento. É direcionado aos processos educacionais de Matemática para $5^{\circ}$ anos e as séries finais do Ensino Fundamental II.

Tal OA foi desenvolvido conforme a definição defendida pelo Grupo de Pesquisa sobre Tecnologias na Educação Matemática $\left(\mathrm{GPTEM}^{17}\right)$, que considera OA como sendo "qualquer recurso virtual multimídia, que pode ser usado e reutilizado com o intuito de dar suporte a aprendizagem de um conteúdo específico, por meio de atividade interativa, apresentada na forma de animação ou simulação" (Kalinke \& Balbino, 2016, p.25).

O objeto já havia sido criado e aplicado anteriormente por Meireles (2017) e Zoppo $(2017)^{18}$, mas necessitava de adequações e alterações em sua programação. Como tais pesquisadoras fazem parte de um mesmo grupo de pesquisa (GPTEM), que considera que as tecnologias se modificam conforme as necessidades que as contextualizam, podendo haver re(elaborações) e continuações de estudos acerca de determinado recurso tecnológico, Nesi (2018b), neste viés, reformulou tal objeto buscando melhorias nos aspectos de usabilidade. Para isso, baseou seus estudos em Meireles (2017) e Zoppo (2017), e em autores que tratavam da usabilidade em OA como Lima et al. (2007), Ferraresso (2014) e Koshiyama (2014).

A respeito do objeto, este apresenta em seu menu inicial opções para Jogar, Tutorial, Descobrindo a Matemática e Criadores. No botão “Jogar” é ofertado ao usuário um jogo digital. Neste ele deve escolher um personagem e percorrer um bairro virtual, explorando locais,

\footnotetext{
${ }^{16}$ A pesquisadora também adotou a mesma definição apresentada anteriormente em Silva (2018).

${ }^{17}$ Site oficial do grupo disponível em: <https://gptem5.wixsite.com/gptem>. Acesso em 02 abr. 2020.

${ }^{18}$ Em suas pesquisas de mestrado, Meireles (2017) e Zoppo (2017) desenvolveram e aplicaram, respectivamente, o OA "Descobrindo Comprimentos" a estudantes de $5^{\circ}$ ano do Ensino Fundamental I e perceberam que algumas melhorias poderiam ser realizadas neste, dando a entender que no quesito da usabilidade algumas adequações poderiam contribuir para aperfeiçoá-lo (Nesi, 2018).
} 
encontrando e respondendo desafios matemáticos. O botão "Descobrindo a Matemática", traz algumas curiosidades e informações referentes ao conteúdo específico de que trata o objeto. O botão "Tutorial" apresenta, em formato de áudio e imagens, indicações de como usar o OA. Por fim, o botão "Criadores" mostra os envolvidos nos processos de criação e reformulação da versão original do objeto, e da atual, versão 2.0.

O OA está alocado no repositório do $\mathrm{Scratch}^{19}$ e também no site do GPTEM ${ }^{20}$. O usuário poderá acessá-lo e usá-lo como recurso educacional. Caso queira reformulá-lo ao seu contexto escolar, poderá realizar modificações na linguagem de programação do Scratch, propiciando uma continuidade na sequência de ciclos de reformulação do respectivo objeto.

Por meio de seus estudos teóricos, Nesi (2018b) identificou que para aprimorar a usabilidade de OA é necessário garantir interfaces atrativas, mobilidade dos avatares, interatividade entre estudante e os elementos do objeto, e clareza das informações. Sendo assim, tal objeto pode auxiliar nos processos de ensino e de aprendizagem, possibilitando aos envolvidos formas diferentes de explorar e construir conhecimentos matemáticos.

O ponto positivo quanto desse produto é que o mesmo pode ser utilizado em smartphones e tablets, tanto na versão online, quanto offline. Percebemos como ponto negativo, a restrição de acesso de laboratório de informática e de computadores, resultando em adequações de uso em outros espaços da escola.

O produto educacional apresentado ao PPGFCET por Silva (2018a), é o Objeto de Aprendizagem (OA) "O skate e a trigonometria" 21 , direcionado ao ensino da trigonometria no triângulo retângulo, sob o viés do movimento histórico e lógico. Para criação deste, a pesquisadora baseou seus estudos nos princípios da teoria histórico-cultural de Vygotsky (1991) e do estudo do par dialético histórico e lógico, fundamentados na teoria materialista históricodialética de Karl Marx (1818-1883) e Friedrich Engels (1820-1895).

Referente ao OA, esse foi criado no software Scratch no formato de jogo educacional digital e é composto por atividades que evidenciam generalidades do movimento histórico e lógico da trigonometria, de modo a suscitar momentos de mediação do professor para promover a formação do pensamento teórico dos estudantes. Em sua interface inicial, há dois botões de acesso: Tutorial e Jogar. O botão “Tutorial” apresenta informações textuais sobre o conteúdo

\footnotetext{
${ }^{19}$ Disponível em: <https://scratch.mit.edu/projects/259918701>. Acesso em: 02 abr. 2020.

${ }^{20}$ Disponível em: <https://gptem5.wixsite.com/gptem/sobre-1>. Acesso em: 02 abr. 2020.

${ }^{21}$ A pesquisadora também adotou a mesma definição apresentada anteriormente em Nesi (2018).
} 
proposto no OA e a forma de pontuação do jogo. No botão "Jogar", é apresentado ao estudante a interação entre dois personagens na busca pela resolução de um determinado problema trigonométrico. Durante tal busca, o estudante é convidado a participar da exploração do OA, contando com momentos de mediação pelo professor. O jogo é finalizado após o estudante encontrar a resposta correta do referido problema.

O OA está disponível no repositório ${ }^{22}$ do Scratch e pode ser acessado e jogado tanto na versão online, quanto offline. Também há a possibilidade de modificá-lo, alterando a sua linguagem de programação e o adaptando para outras especificidades educacionais. Neste viés, Silva (2018a, 2018b) sugere a inclusão de novas situações de ensino sobre trigonometria na circunferência. Tal indicação, oportuniza uma continuação de estudos na criação e/ou reformulação de OA no movimento histórico e lógico.

Por fim, a pesquisadora salienta que o OA busca propiciar o trabalho e discussões coletivas, oportunizando interação entre professor e estudantes na busca da construção do pensamento teórico a partir da necessidade dos conceitos trigonométricos, conferindo indícios da teoria histórico-cultural e do par dialético histórico e lógico.

Constatamos como ponto positivo no produto, a possibilidade de explorar a História da Matemática a fim de propiciar formas diferentes de ensinar e de aprender a trigonometria no triângulo retângulo. Outro ponto a favor, é que o OA pode ser utilizado em tablets e smartphones na versão online e offline. Um ponto negativo é a restrição quanto ao uso de laboratório de informática e computadores, o que pode implicar em propostas diferentes quanto ao uso do OA em sala de aula.

O produto educacional apresentado ao PPGMAT por Curci (2017a), trata de um guia didático para suporte ao docente na programação de OA matemáticos por meio do software Scratch. Este produto foi construído no decorrer de sua pesquisa mediante etapas de aplicação de um curso de formação inicial de professores do curso de Licenciatura em Matemática, da Universidade Estadual do Paraná (UNESPAR), do Campus Apucarana.

O guia didático está dividido em seis capítulos: Tela inicial e introdução ao Scratch; Movimentando atores e desenhando padrões; Criando animações e introduzindo sons; Blocos personalizados e broadcasting; As variáveis no Scratch; e As listas no Scratch. Em cada um, há apresentação e explicação dos principais comandos do Scratch, além de sugestões de atividades

\footnotetext{
${ }^{22}$ Disponível em <https://scratch.mit.edu/projects/236986943/>. Acesso em 02 abr. 2020.
} 
referente ao conteúdo de Geometria na Educação Básica. O acesso a tal produto se dá por meio do RIUT, em produções acadêmicas da respectiva pesquisadora.

Curci (2017b) fundamentou seus estudos em autores da área da educação que tratam do uso de tecnologias educacionais como Valente (1999), Borba e Penteado (2012), Balbino (2014), Kalinke (2015) e Motta (2008). A respeito da formação de professores, direcionou olhares ao trabalho de Tardif (2010) e documentos oficiais de ensino (PCN). Por meio desses, constatou que o uso do Scratch para o desenvolvimento de OA, contribuiu na formação inicial de professores no ensino de conceitos geométricos, possibilitando reflexões e aprendizagens relevantes à formação. Logo, o produto educacional pode ser explorado por professores visando a produção de artefatos digitais, vindo a contribuir nos processos educacionais de Matemática.

Um dos pontos positivos quanto a esse produto, é que o mesmo pode ser utilizado tanto na formação inicial do professor, quanto na continuada, oportunizando a difusão do uso de linguagem de programação intuitiva na construção de objetos na área educacional. Também, seu uso pode dar-se na versão offline, o que favorece a exploração do Scratch. Algo desfavorável, quanto ao uso desse software e dos objetos construídos nele, é a questão da restrição quanto ao uso de laboratório de informática e computadores da escola.

Gomes (2017a) expôs como produto educacional ao PPGMAT, o material "Afinal, como surgiram as geometrias não euclidianas?”. Este é composto por quatro sequências de atividades contendo indicações de uso de vídeos e atividades baseadas na História da Matemática e a geometria não euclidiana. O mesmo foi produzido e aplicado a um curso de formação continuada de professores de Matemática que atuavam na Educação Básica no município de Leópolis/PR. A intenção foi propiciar aos cursistas uma reflexão a respeito das geometrias não euclidianas em contexto histórico matemático (Gomes, 2017b). Segundo o pesquisador, tal material foi desenvolvido atendendo alguns autores que tratam da formação do professor e a História da Matemática (D’Ambrósio, 1996; Martins, 2007; Machado \& Mendes, 2013), e o uso pedagógico de tecnologias, como os vídeos, no contexto da Educação Matemática (Moran, 1995; Borba; 1999; Ponte, 2000; Kenski, 2003).

Sobre as quatro sequências de atividades, Gomes (2017a) propôs para cada uma: informações quanto ao tema a ser abordado, link de acesso ao vídeo produzido e alocado no 
Youtube $^{23}$, e propostas de atividades sobre o assunto exposto. A primeira atividade trata da origem das geometrias não euclidianas; a segunda se refere ao estudo das retas paralelas nas geometrias hiperbólica e elíptica; a terceira tange aos triângulos nas geometrias hiperbólica e elíptica; e a quarta diz respeito sobre aos quadriláteros nas geometrias hiperbólica e elíptica. Para acessar tal produto, o mesmo está disponível no RIUT em produções acadêmicas do respectivo autor.

A respeito do ponto positivo do produto, elencamos a possibilidade de o professor retomar a História da Matemática, buscando compreensões e construções de conhecimentos dos alunos sobre geometrias hiperbólica e elíptica. Além do que, o professor pode adequar tais atividades conforme seu interesse pedagógico. Um ponto negativo, é a questão do acesso à internet para exploração dos vídeos, restringindo seu uso caso a mesma não esteja disponível à escola e alunos.

Morais (2017a) apresentou ao PPGMAT o produto educacional vlog "Desmistificando a Matemática por Meio da Estatística ${ }^{24}$. Este foi elaborado por meio da plataforma online wix.com, ofertando seis vídeoaulas, contendo atividades e sugestões de estudo para o professor ensinar o conteúdo de Estatística para estudantes de $7^{\circ}$ ano do Ensino Fundamental II. Tais materiais pedagógicos foram elaborados segundo as Diretrizes Curriculares Estaduais, tendo como apoio os Parâmetros Curriculares Nacionais e Lei de Diretrizes e Bases da Educação Básica (LDB nº 9394/96) (Morais, 2017b).

O vlog disponibiliza seis ícones: Página inicial; Sobre; Videoaulas; Atividades; Sugestões de pesquisa; e Contato. A Figura 2 a seguir, apresenta a interface inicial do mesmo.

Figura 2 - Vlog "Desmistificando a Matemática por Meio da Estatística"

\footnotetext{
23 Disponível em: <https://www.youtube.com/watch?v=eqjKgzx 7fLk\&t=4s>; <https://www.youtube.com/watch?v=ZvuzbE0FP3E>; <https://www.youtube.com/watch?v=YIW-q11QNhY>; <https://www.youtube.com/watch?v=ia9pzMeVUEU>. Acesso em 20 abr. 2020.

${ }^{24}$ Disponível em: <https://daianemiliossi.wixsite.com/vlogdematematica>. Acesso em 22 abr. 2020.
} 


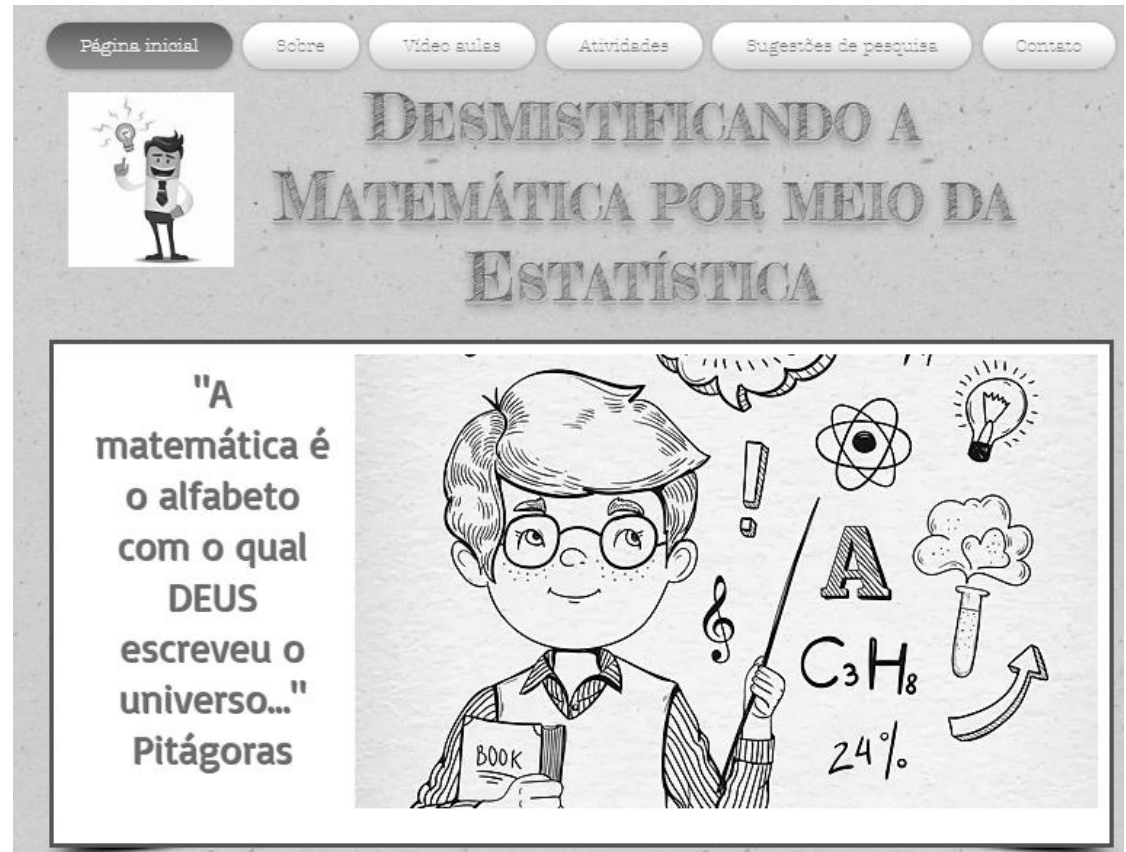

Fonte: < https://daianemiliossi.wixsite.com/vlogdematematica >. Acesso em 22 abr. 2020

A "Página inicial" remete a interface inicial do vlog, como apresentada na figura anterior. No ícone "Sobre", há informações sobre os criadores do projeto. Na aba "Vídeoaulas" localizase o material pedagógico produzido por meio de vídeos para o ensino de Estatística. Em “Atividades" é disponibilizado ao professor e ao aluno, materiais para download com exercícios a respeito das vídeoaulas, que podem ser utilizados como forma de auxílio nos processos educacionais. Na parte "Sugestões de pesquisa", são apresentadas dicas de materiais complementares, como textos e sites com informações sobre o tema Educação e Estatística. Em “Contato", o usuário pode deixar alguma dúvida ou sugestão a respeito do material do $v \log$.

Referente às vídeoaulas, essas foram separadas por seis temas: O que é estatística; Classificação de variáveis ou dados; População e amostra; Média; Moda e Mediana. São seis vídeos com duração entre dois a três minutos. Segundo Morais (2017a), o professor pode expor a parte teórica do conteúdo, em seguida apresentar vídeo sobre o respectivo assunto e finalizar com atividades que tratem do que foi elucidado, oportunizando ao estudante associar a teoria com sua prática vivenciada extraclasse. Logo, o vlog pode permitir olhares diferenciados na construção de conhecimentos.

Analisando tal produto educacional, notamos como ponto positivo a disponibilidade do vlog por meio da web, podendo o estudante explorá-lo mediante computador ou smartphone/tablet. Outra conveniência é a possibilidade de reformular as atividades aos 
estudantes do Ensino Fundamental II e Ensino Médio, pois o conteúdo de Estatística é abordado nestas etapas educacionais. Um dos pontos negativos, é que em seu material digital no RIUT, não é possível acessar o link para o vlog, tão pouco das videoaulas. Isto faz com que o leitor, para ter acesso aos mesmos, deva acessar a dissertação da pesquisadora e buscar tal material. Outro ponto negativo é sobre o acesso e a velocidade da internet da escola por meio de computadores ou smartphones/tablets, limitando a exploração do respectivo produto.

Pereira (2018a) apresentou como produto educacional ao PPGMAT, um guia para a criação de $\mathrm{OA}^{25}$ matemáticos por meio da ferramenta de Autoria para a Remediação de erros com Mobilidade na Aprendizagem (FARMA ${ }^{26}$ ). Segundo o pesquisador, tal ferramenta visa a construção de OA digitais, estruturados por introduções e exercícios, ou seja, criam-se enunciados e a partir deles, propõem-se situações-problemas com respostas em forma de expressões aritméticas ou algébricas.

O mesmo desenvolveu nove OA de Geometria e os aplicou aos estudantes de nono ano do Ensino Fundamental de uma escola pública de São Paulo/SP, a fim de constatar mudanças de concepções a respeito de definições prévias sobre conceitos básicos de geometria. Para tanto, Pereira (2018b) baseou seus estudos em autores que tratam do Ensino de Matemática e Tecnologia, como Kenski (2010), Papert (1994), Borba, Scucuglia e Gadanidis (2014), Motta (2008) e Curci (2017). Também expõe a teoria Construcionista de Papert (1994) para compreensão da construção do aprendizado do estudante por meio das TD.

No que tange aos nove OA elaborados, um deles aborda Elementos Básicos da Geometria, dois sobre Formas Geométricas, um sobre Perímetro de Figuras Geométricas, um sobre Ângulos, um sobre Polígonos, um sobre Circunferências e Círculos, um sobre Ângulos e Arcos de uma Circunferência, e um sobre Teoremas. Tais objetos apresentam interfaces de introdução do conteúdo e na sequência, são propostas atividades sobre o respectivo assunto.

Para acessá-los e utilizá-los, o professor deverá se registrar e criar uma conta no FARMA. Pereira (2018a) salienta que o professor pode utilizar a opção "Criar Turma" para selecionar e disponibilizar aos estudantes, objetos específicos à serem explorados. Isto pode facilitar uma maior organização do trabalho pedagógico, além de acompanhar simultaneamente

\footnotetext{
${ }^{25} \mathrm{O}$ pesquisador não especificou em sua dissertação, qual a compreensão ou definição adotada para construção de OA.

${ }^{26}$ Disponível em: <http://farma.educacional.mat.br/>. Acesso em 02 abr. 2020.
} 
o progresso dos estudantes. Para acessar tais objetos, o estudante deve fazer cadastro na turma criada, mediante código de acesso disponibilizado pelo FARMA ao professor.

O pesquisador interpreta que por meio da utilização dos OA, houve uma modificação no modo de pensar dos estudantes em relação a conceitos básicos de geometria, propiciando a aprendizagem dos conteúdos apresentados. Com relação ao FARMA, Pereira (2018b) notou que ele é uma ferramenta que pode favorecer um ambiente dinâmico de ensino, vindo a promover conhecimentos matemáticos. Também destaca que, por ser de fácil uso na construção de OA, pode atender as demandas de professores que não tenham tanta familiaridade com o uso de TD, promovendo novas criações e divulgações de objetos.

Podemos apontar como ponto positivo do produto, a questão da acessibilidade. O mesmo pode ser explorado por meio da web, na plataforma FARMA, em diferentes aparelhos móveis. O ponto negativo é que o produto está alocado em site online, logo, caso a escola não possua sinal de internet ou esteja com velocidade baixa, os OA não poderão ser investigados com tal conexão, recorrendo ao uso da rede de dados privada do aluno e/ou do professor, como apontado em Elias (2018).

O produto educacional de Cardoso (2019b), entregue ao PPGMAT, é o "Mapas e contornos: caminhos para o ensino de Estatística no RStudio". Esse é um manual direcionado aos professores para o ensino da Estatística à Educação Básica, em que apresenta os principais comandos do software RStudio, utilizando os pacotes Swirl e Swirlify, para a programação de atividades. Tal software é escrito na linguagem de programação C++.

Nesse manual, há informações quanto a instalação do respectivo software e pacotes de comandos, seguido de instruções passo a passo de como criar atividades educacionais. De acordo com a pesquisadora, fica a critério do professor em definir qual o conteúdo e a quantidade de atividades a serem desenvolvidas. Ao acesso ao respectivo produto, o mesmo encontra-se no RIUT, em produções acadêmicas do respectivo autor.

Com relação ao desenvolvimento do produto, Cardoso (2019a) buscou na literatura autores que abordavam sobre o Ensino da Estatística (Webster, 2006; Ignácio, 2010; Santos et al., 2016) e o uso de Tecnologias Digitais na Educação (Moura, 2010; Vasconcelos, 2014; Carvalho e Costa, 2006), além de informações sobre o pacote Swirl e o software RStudio, para criação e desenvolvimento de atividades em linguagem de programação. Durante a pesquisa, aplicou o produto a uma turma de $8^{\circ}$ ano do Ensino Fundamental II, de uma escola da rede 
particular de Londrina/PR, com o objetivo de compreender o impacto do software RStudio aplicado aos conteúdos de Estatística, analisando a aceitação do programa por parte dos estudantes. Após aplicação, a pesquisadora constatou que a utilização do software oportunizou melhorias significativas na aprendizagem dos estudantes, além de promover a interação entre os envolvidos.

Algo positivo quanto ao produto, é a possibilidade do professor entrar em contato com uma linguagem de programação a fim de desenvolver atividades específicas de seu componente curricular. Outro ponto favorável, é que o software RStudio pode ser usado com ou sem acesso à internet. Destacamos como ponto negativo, o manual é estritamente técnico sem se preocupar com o quesito pedagógico. Nesta perspectiva, dicas como atividades de Estatística poderiam tornar o material mais atrativo ao professor.

Investigando o produto educacional de Coutinho (2019a) ao PPGMAT, este é um material contendo informações e atividades quanto ao ensino de "Divisão e Multiplicação de Polinômios com o auxílio de Materiais Manipuláveis e Tecnologias”. Apresentando sequências de atividades matemáticas com Material Manipulável e GeoGebra. Estas foram desenvolvidas seguindo a Teoria de Registro de Representação Semiótica de Raymond Duval (2003), que pressupõe que os objetos matemáticos são acessíveis exclusivamente por meio de suas representações semióticas, sendo que a diversidade enriquece a aprendizagem matemática.

Tais atividades foram elaborados para uma turma de $8^{\circ}$ ano, de uma escola da rede privada de Campo Mourão/PR. Após a aplicação e análise de dados, a pesquisadora reformulou as mesmas e compôs o produto educacional. Esse propõe a aplicação das atividades em duas etapas: utilizando recursos com Material Manipulável (MM) e software GeoGebra online, visando o ensino de multiplicação e divisão de polinômios a partir da área de um retângulo. Sugere que as atividades sejam realizadas seguindo a Metodologia Ativa de Rotação por Estação do Ensino Híbrido, em que os alunos são divididos em grupos, e por meio de rodízio exploram propostas de trabalhos/atividades em estações específicas. Segundo a pesquisadora, tais materiais e metodologia podem despertar o interesse dos alunos pelo conteúdo proposto de polinômios. O acesso a esse produto educacional, dá-se por meio do RIUT, em produções da respectiva pesquisadora.

Atentamos como ponto positivo no produto, a variedade de atividades propostas tanto com MM, quanto no GeoGebra, para despertar no estudante representações em escrita em língua 
natural e algébrica de polinômios. Ademais, o GeoGebra pode ser utilizado tanto na versão online, quanto offline. Um ponto negativo é que não identificamos de forma clara, tanto no produto, quanto na dissertação, se as atividades com o respectivo software ocorreram em laboratório de informática. Pela leitura compreendemos que foram realizadas em sala de aula. Tal observação se faz pertinente, pois geralmente os computadores estão em laboratório de informática ou locais restritos aos funcionários da escola. Logo, cabe uma notação que o uso do GeoGebra em sala de aula pode dar-se, por meio do computador, notebook, smartphone e tablet, fomentando o uso de TD em contexto educacional.

O produto educacional de Domingues (2019b) ao PPGMAT, é o "Livro Interativo de Realidade Aumentada para o ensino de Estatística”. Esse foi construído baseado em revisão bibliografia sobre livro Interativo com Realidade Aumentada (Oliveira, 2016; Gomes et al., 2015; Veloso, 2011) e por meio do aplicativo HP/Reveal para programar e fazer as leituras de imagens em 3D. Durante a pesquisa, Domingues (2019a) aplicou tal produto em uma turma do sétimo ano do Ensino Fundamental, de uma escola pública de Londrina/PR. Tal experiência visou complementar o ensino de Estatística utilizando o mundo real e o virtual por meio de vídeos. Diante desse processo, considerou que "quando o professor utiliza o celular para mediar as aulas, pode deixá-las mais dinâmicas e mais prazerosas, melhorando a interação entre os alunos; aluno e professor; aluno e tecnologia; aluno, professor, tecnologia e conteúdo" (Domingues, 2019a, p. 88). Nessa percepção, o uso da Realidade Aumentada oportunizou formas diferentes de ensino, modificando as relações e interações entre os envolvidos.

Sobre o livro, esse é composto por quatro sequências: conceito de população e amostra; estudo de tabelas e tipos de gráficos; construção de gráficos de setores; e estudo das tendências centrais. Em cada uma, há uma explanação de como ocorreu a inserção daquele material em sala de aula, seguida de imagens e exercícios em 3D lidas pelo respectivo aplicativo, e finaliza com informativo sobre tempo previsto para aplicação da atividade, metodologia, objetos necessários que o aluno precisa ter, entre outros dados. Tal produto educacional está disponível nas produções acadêmicas do respectivo pesquisador, no RIUT.

Um ponto positivo sobre o produto, é que o mesmo apresenta propostas didáticas com uso de smartphones e Realidade Aumentada para abordar a Estatística, podendo ser utilizado em turmas do Ensino Fundamental II e Médio, cabendo ao professor adequar as atividades quando necessário. Um agravante identificado no produto, é que não conseguimos localizar tal 
aplicativo, nem na Google Play Store ${ }^{27}$ versão web, nem em dispositivo móvel. Buscamos na web informações sobre o mesmo, e observamos que em seu site ${ }^{28}$ há a informação que a HP/Reveal encerrou seus negócios e produtos. Diante disso, atualmente o produto é considerado inativo por meio do respectivo aplicativo.

Buscando organizar a análise apresentada, de forma a facilitar a busca dos trabalhos por professores ou pesquisadores, categorizamos os produtos educacionais de acordo com o formato, proposta, processos educacionais, teoria de aprendizagem e acesso, conforme apresentado no Quadro 2 a seguir.

No formato buscamos estabelecer qual é o tipo do produto educacional; na proposta educacional procuramos identificar o que o produto oferece aos envolvidos na área de Ensino de Matemática; em processos educacionais elencamos qual processo - de ensino e/ou de aprendizagem - o produto se direciona; na teoria de aprendizagem trazemos a concepção teórica em que o produto foi desenvolvido; e no acesso atentamos identificar de que forma o usuário pode acessar o produto educacional.

\begin{tabular}{|c|c|c|}
\hline & & \\
\hline Lat & Bre & \\
\hline \multirow{4}{*}{ Formato } & Programação ou Construção de OA & $\begin{array}{l}\text { Pereira (2017a); Nesi (2018a); Silva } \\
\text { (2018a); Cardoso (2019b) }\end{array}$ \\
\hline & Oficina & Maciel Junior (2017) \\
\hline & Sequência Didática & $\begin{array}{l}\text { Curci (2017a); Gomes (2017a); Elias } \\
\text { (2018b); Coutinho (2019a); Domingues } \\
(2019 b)\end{array}$ \\
\hline & Site & Cruz_(2017); Morais (2017a) \\
\hline \multirow{3}{*}{$\begin{array}{c}\text { Proposta } \\
\text { educacional }\end{array}$} & Programação e/ou uso de OA & $\begin{array}{l}\text { Curci (2017a); Pereira (2017a); Nesi } \\
\text { (2018a); Silva (2018a) }\end{array}$ \\
\hline & Programação e/ou uso de aplicativos & $\begin{array}{l}\text { Cruz (2017); Gomes (2017a); Morais } \\
\text { (2017a); Elias (2018b); Cardoso (2019b); } \\
\text { Coutinho (2019a); Domingues (2019b) }\end{array}$ \\
\hline & Uso da robótica & Maciel Junior (2017) \\
\hline \multirow[t]{3}{*}{$\begin{array}{l}\text { Processos } \\
\text { educacionais }\end{array}$} & Processo de ensino & $\begin{array}{l}\text { Cruz (2017); Curci (2017a); Gomes } \\
\text { (2017a); Maciel Junior (2017); Morais } \\
\text { (2017a); Coutinho (2019a); Domingues } \\
(2019 b)\end{array}$ \\
\hline & Processo de aprendizagem & Elias (2018b) \\
\hline & $\begin{array}{l}\text { Processos educacionais (processos de } \\
\text { ensino e de aprendizagem) }\end{array}$ & $\begin{array}{l}\text { Pereira (2017a); Nesi (2018a); Silva } \\
\text { (2018a); Cardoso (2019b) }\end{array}$ \\
\hline
\end{tabular}

${ }^{27}$ Disponível em: <https://play.google.com/store>. Acesso em 23 abr. 2020.

${ }^{28}$ Disponível em: < https://studio.hpreveal.com/>. Acesso em 23 abr. 2020. 


\begin{tabular}{|c|c|c|}
\hline \multirow{5}{*}{$\begin{array}{c}\text { Teoria de } \\
\text { aprendizagem }\end{array}$} & $\begin{array}{l}\text { Teoria Aprendizagem Significativa } \\
\text { (Ausubel, 1980) }\end{array}$ & Elias (2018b) \\
\hline & Teoria Construcionista (Papert, 1986) & Pereira (2017a); Elias (2018b) \\
\hline & $\begin{array}{l}\text { Teoria histórico-cultural (Vygotsky, } \\
\text { 1991) }\end{array}$ & Silva (2018a) \\
\hline & $\begin{array}{l}\text { Teoria materialista histórico-dialética } \\
\text { (Marx, 1818-1883; Engels, 1820- } \\
\text { 1895). }\end{array}$ & Silva (2018a) \\
\hline & $\begin{array}{l}\text { Teoria de Registro de Representação } \\
\text { Semiótica (Durval, 2003) }\end{array}$ & Coutinho (2019a) \\
\hline \multirow[t]{2}{*}{ Acesso } & Site específico & $\begin{array}{l}\text { Cruz (2017); Morais (2017a); Pereira } \\
\text { (2017a); Elias (2018b); Nesi (2018a); Silva } \\
\text { (2018a) }\end{array}$ \\
\hline & RIUT (produção acadêmica do autor) & $\begin{array}{l}\text { Curci (2017a); Gomes (2017a); Maciel } \\
\text { Junior (2017); Cardoso (2019b); Coutinho } \\
\text { (2019a); Domingues (2019b) }\end{array}$ \\
\hline
\end{tabular}

Fonte: os autores (2020)

A opção da citação dos autores se deu pela busca de não sobrecarregar informações no quadro anterior. Os autores foram elencados seguindo a ordem cronológica de suas publicações.

Os dados apresentados no Quadro 2, nos dão um panorama de que um número expressivo de pesquisadores atenta aos produtos educacionais nos formatos de sequências didáticas. Isso vai ao encontro de que a maioria deles, importa-se com o processo de ensino. Outro destaque, cabe de que os produtos educacionais investigados também ofertam cursos, guias didáticos e oficina mediante uso de softwares educacionais e aplicativos, a fim de promover o uso de TD aos envolvidos nos processos educacionais de Matemática. Na sequência, apresentamos nossas considerações finais referentes aos mesmos.

\section{Considerações}

Por meio desta pesquisa, verificamos que os produtos educacionais produzidos recentemente nos Programas de Mestrado Profissional da UTFPR - PPGECT de Ponta Grossa, PPGFCET de Curitiba e PPGMAT de Cornélio Procópio e Londrina - direcionados ao Ensino Fundamental II e Ensino Médio mediante uso de TD, estão sinalizados a contribuírem nos processos educacionais de Matemática na Educação Básica.

Uma característica marcante na maioria dos produtos condiz com seu formato, pois são sequências didáticas para o ensino de conteúdos matemáticos, mediante uso de programação e/ou uso de aplicativos, dando indícios que o processo de ensino é uma preocupação ao uso de 
TD no ambiente educacional. Os demais focam em oficinas, sites e uso de softwares e de aplicativos para os processos educacionais de Matemática.

Acentuamos como ponto positivo, que os produtos investigados podem ser encaminhados para o uso tanto do professor, quanto do estudante. Desta forma, o material apresentado pode ser utilizado pelo professor a fim de propiciar metodologias diferenciadas para o ensino de determinado conteúdo, e para os estudantes possibilitando a exploração de diferentes tecnologias para a aprendizagem. Essa constatação vai ao encontro do pensamento de Elias, Motta e Kalinke (2018), de que a inserção de TD pode preparar e despertar o professor o gosto de utilizar algum recurso tecnológico. Essa ação permite o uso de meios digitais pelos estudantes, podendo modificar e ressignificar processos cognitivos.

Evidenciamos que alguns produtos viabilizaram a programação em softwares específicos, possibilitando metodologias diferenciadas para investigação lógica-matemática nas explorações de diferentes linguagens de programações. Nesse viés, identificamos em Balbino, Nesi e Kalinke (2018) a compreensão de que a criação de atividades em softwares educacionais pode transformar o modo do professor ensinar mediante metodologias não tradicionais, e oportunizar aos estudantes, investigações pela busca do conhecimento por meio das TD.

Outra observação a ser destacada, condiz ao desenvolvimento do produto considerando alguma teoria de aprendizagem. Os produtos criados especificamente sob alguma teoria, atenderam o solicitado na investigação quanto a construção do conhecimento pelo estudante, trazendo um olhar atento quanto aos processos cognitivos.

Notamos que os produtos viabilizam acessos similares por meio de repositórios e sites específicos como Facebook, Scratch, App Inventor, FARMA e vlog. Alguns estão apenas disponíveis mediante consulta em dissertação (Cruz, 2017; Maciel Junior, 2017) ou não estão ao dispor no momento, como o site Tecnomatematica (Cruz, 2017) e o Livro Interativo de Realidade Aumentada para o ensino de Estatística (Domingues, 2019b). Consequentemente, vemos uma equivalência de disponibilidade dos mesmos, tanto por sites específicos, quanto por meio do RIUT. Esse movimento vai ao encontro do solicitado em Relatório de Avaliação Quadrienal CAPES (Brasil, 2017), de que os produtos precisam ser registrados em formato digital e disponibilizados nos sites ou repositórios das respectivas instituições.

Nesta direção, destacamos como um limitante o acesso dos mesmos mediante a disponibilidade da internet. Levantamos tal quesito pois em algumas escolas a velocidade da 
internet é precária, ou simplesmente não há, dificultando o acesso online por meio de computadores, smartphones e tablets. Uma possibilidade para evitar tal situação, confere a utilização de versões offline desses produtos, isso quando o respectivo software ou aplicativo promove tal viabilidade.

Por fim, constatamos nessa investigação que tais materiais podem ser utilizados e adequados conforme o planejamento didático do professor, levando em consideração a necessidade de adequação ao contexto escolar. Perante isso, indicamos uma continuidade em pesquisas que visem à criação de produtos educacionais que priorizem o Ensino de Matemática mediante uso de TD, a fim de divulgar e promover metodologias diferenciadas que possam contribuir com melhorias para a Educação no cenário nacional.

\section{Referências}

Balbino, R. O., Nesi, T. L. e Kalinke, M. A. (2018, 30 maio-01 junho). Scratch: do primeiro olhar à programação no Ensino Médio. V Seminário Internacional de Pesquisa Qualitativa e Estudo Qualitativos, SIPEQ, Foz do Iguaçu, PR. https://sepq.org.br/eventos/vsipeq/documentos/02470907942/11

Belloni, M. L. (1999). Mediatização: Os desafios das novas tecnologias de informação e comunicação. In: Belloni, M. L. Educação a Distância (pp. 53-77). Campinas: Editora Autores Associados, 1999.

Brasil (2019). Ministério da Educação. Coordenação de Aperfeiçoamento de Pessoal de Nível Superior (CAPES). Documento de Área 46. Área de Ensino. http://capes.gov.br/images/Documento_de_\%C3\%A1rea_2019/ENSINO.pdf

Brasil (2017). Ministério da Educação. Coordenação de Aperfeiçoamento de Pessoal de Nível Superior (CAPES). Relatório de Avaliação Quadrienal. https://capes.gov.br/images/stories/download/avaliacao/relatorios-finais-quadrienal2017/20122017-ENSINO-quadrienal.pdf

Cardoso, M., G. (2019a). Ensino de Estatística: o estudo de conceitos potencializado pelo software RStudio [Dissertação de Mestrado em Ensino de Matemática, Universidade Tecnológica Federal do Paraná]. http://repositorio.utfpr.edu.br/jspui/handle/1/4704

Cardoso, M., G. (2019b). Mapas e contornos: caminhos para o ensino de Estatística no RStudio [Produto Educacional de Mestrado em Ensino de Matemática, Universidade Tecnológica Federal do Paraná]. http://repositorio.utfpr.edu.br/jspui/handle/1/4704

Coutinho, D., M. (2019a). Atividades para ensinar multiplicação e divisão de polinômios [Produto Educacional de Mestrado em Ensino de Matemática, Universidade Tecnológica Federal do Paraná]. http://repositorio.utfpr.edu.br/jspui/handle/1/4024 
Coutinho, D., M. (2019b). Divisão e multiplicação de polinômios com o auxílio de materiais manipuláveis e tecnologias sob o olhar da representação semiótica [Dissertação de Mestrado em Ensino de Matemática, Universidade Tecnológica Federal do Paraná]. http://repositorio.utfpr.edu.br/jspui/handle/1/4024

Cruz, F. M. (2017). Tecnomatemática: site como ferramenta tecnológica para o ensino de frações no $6^{\circ}$ ano do ensino fundamental [Dissertação de Mestrado em Ensino de Ciência e Tecnologia, Universidade Tecnológica Federal do Paraná]. http://repositorio.utfpr.edu.br/jspui/handle/1/2999

Curci, A. P. F. (2017a). Produto Educacional: Contribuições ao Ensino de Geometria por meio da criação de Objetos de Aprendizagem [Produto Educacional de Mestrado em Ensino de Matemática, Universidade Tecnológica $\quad$ Federal do Paraná]. http://repositorio.utfpr.edu.br/jspui/handle/1/3039

Curci, A. P. F. (2017b). O software de programação Scratch na formação inicial do professor de matemática por meio da criação de objetos de aprendizagem. [Dissertação de Mestrado em Ensino de Matemática, Universidade Tecnológica Federal do Paraná]. http://repositorio.utfpr.edu.br/jspui/handle/1/3039

Diniz, C. S. (2015). Lousa Digital como ferramenta pedagógica na visão de professores de Matemática [Dissertação de Mestrado em Educação em Ciências e em Matemática, Universidade Federal do Paraná]. https://acervodigital.ufpr.br/handle/1884/41457

Domingues, M., A., F., G. (2019a). A utilização do smartphone com intermédio de um aplicativo de realidade aumentada para a aprendizagem de Estatística [Dissertação de Mestrado em Ensino de Matemática, Universidade Tecnológica Federal do Paraná]. http://repositorio.utfpr.edu.br/jspui/handle/1/4701

Domingues, M., A., F., G. (2019b). Livro interativo de Realidade Aumentada para o Ensino de Estatística [Produto Educacional de Mestrado em Ensino de Matemática, Universidade Tecnológica Federal do Paraná]. http://repositorio.utfpr.edu.br/jspui/handle/1/4701

Elias, A. P. J. A. (2018a). Possibilidades de utilização de smartphones em sala de aula: construindo aplicativos investigativos para o trabalho com equações do $2^{\circ}$ grau [Dissertação de Mestrado em Formação Científica, Educacional e Tecnológica, Universidade Tecnológica Federal do Paraná]. http://repositorio.utfpr.edu.br/jspui/handle/1/3897

Elias, A. P. J. A. (2018b). Produto Educacional - Possibilidades de utilização de smartphones em sala de aula: construindo aplicativos investigativos para o trabalho com equações do $2^{o}$ grau [Produto Educacional de Mestrado em Formação Científica, Educacional e Tecnológica, Universidade Tecnológica $\quad$ Federal do Paraná]. http://repositorio.utfpr.edu.br/jspui/handle/1/3897

Elias, A. P. J. A., Hussein, F. R. G. S. e Motta, M. S. (2018). Uma proposta interdisciplinar para o desenvolvimento de aplicativos de matemática financeira em um Curso de Graduação em 
Engenharia Elétrica. Tear - Revista de Educação Ciência e Tecnologia, 7 (1), 1-20. https://periodicos.ifrs.edu.br/index.php/tear/article/view/2740

Elias, A. P. J. A., Motta, M. S. e Kalinke, M. A. (2018). Construção de Objetos de Aprendizagem para a Educação Básica por Meio de um Curso Sobre o Scratch para Estudantes de Licenciaturas. RENOTE - Revista Novas Tecnologias na Educação, 16 (2), 423-433. https://seer.ufrgs.br/renote/article/view/89258

Fiorentini, D., Grando, R. C., Miskulin, R. G. S., Crecci, V. M., Lima, R. C. R. e Costa, M. C. (2016). O professor que ensina Matemática como campo de estudo: concepção do projeto de pesquisa. In: Fiorentini, D. et al. (Orgs.). Mapeamento da pesquisa acadêmica brasileira sobre o professor que ensina Matemática: período 2001 - 2012. Campinas, SP: FE/UNICAMP.

Gomes, L. F. (2017a). Afinal, como surgiram as Geometrias não euclidianas? [Produto Educacional de Mestrado em Ensino de Matemática, Universidade Tecnológica Federal do Paraná]. http://repositorio.utfpr.edu.br/jspui/handle/1/2404

Gomes, L. F. (2017b). Vídeos didáticos e atividades baseadas na história da matemática: uma proposta para explorar as geometrias não Euclidianas na formação docente [Dissertação de Mestrado em Ensino de Matemática, Universidade Tecnológica Federal do Paraná]. http://repositorio.utfpr.edu.br/jspui/handle/1/2404

Kenski, V. M. (2012). Educação e Tecnologias: O novo ritmo da informação. Campinas, SP: Papirus.

Lévy, P. (2010). As tecnologias da inteligência: o futuro do pensamento na era da informática. São Paulo: Editora 34, 2 ed.

Maciel Junior, P. F. (2017). Uma proposta de estudo da autonomia docente de professores de Ciências e de Matemática em exercício [Dissertação de Mestrado em Formação Científica, Educacional e Tecnológica, Universidade Tecnológica Federal do Paraná]. http://repositorio.utfpr.edu.br/jspui/handle/1/2884

Morais, D. A. M. (2017a). Desmistificando a Matemática por meio da Estatística [Produto Educacional de Mestrado em Ensino de Matemática, Universidade Tecnológica Federal do Paraná]. http://repositorio.utfpr.edu.br/jspui/handle/1/3047

Morais, D. A. M. (2017b). Uma aplicação de vlogs nas aulas de estatística na educação básica [Dissertação de Mestrado em Ensino de Matemática, Universidade Tecnológica Federal do Paraná]. http://repositorio.utfpr.edu.br/jspui/handle/1/3047

Motta, M. S., Kalinke, M. A. e Curci, A. P. F. (2019). Um produto educacional para orientar a criação de objetos de aprendizagem Matemática no software de programação Scratch. Revista de Educação, Ciências e Matemática, $\quad 9(1), \quad 238-251$. http://publicacoes.unigranrio.edu.br/index.php/recm/article/view/5104 
Nesi, T. L. (2018a). Objeto de Aprendizagem “Descobrindo Comprimentos” versão 2.0 [Produto Educacional de Mestrado em Formação Científica, Educacional e Tecnológica, Universidade Tecnológica $\quad$ Federal do Paraná]. http://repositorio.utfpr.edu.br/jspui/handle/1/3764

Nesi, T. L. (2018b). Reformulando um objeto de aprendizagem criado no Scratch: em busca de melhorias na usabilidade [Dissertação de Mestrado em Formação Científica, Educacional e Tecnológica, Universidade Tecnológica Federal do Paraná]. http://repositorio.utfpr.edu.br/jspui/handle/1/3764

Nesi, T. L., Kalinke, M. A., Balbino, R. O., Renaux, C. D. Z., Heleno, S. M. G. e Essenfelder, A. M. (2018). Revisando conteúdo matemático por meio de um Objeto de Aprendizagem criado no software Scratch. I Encontro Paranaense de Tecnologia na Educação Matemática - EPTEM, Apucarana,

PR. http://www.sbemparana.com.br/eventos/index.php/EPTEM/I_EPTEM/schedConf/presentation $\mathrm{s}$

Pereira, F. H. (2018a). Produto Educacional: Um estudo sobre o ensino de geometria com o uso da FARMA [Produto Educacional de Mestrado em Ensino de Matemática, Universidade Tecnológica Federal do Paraná]. http://repositorio.utfpr.edu.br/jspui/handle/1/3441

Pereira, F. H. (2018b). Um estudo sobre o ensino de geometria com o uso da FARMA [Dissertação de Mestrado em Ensino de Matemática, Universidade Tecnológica Federal do Paraná]. http://repositorio.utfpr.edu.br/jspui/handle/1/3441

Richit, A., Mocrosky, L. F. e Kalinke, M. A. (2015). Tecnologias e prática pedagógica em matemática: tensões e perspectivas evidenciadas no diálogo entre três estudos. In: Kalinke, M. A., Mocrosky, L. F. (Orgs.). Educação Matemática: pesquisas e possibilidades (pp. 117-140). Curitiba: Ed. UTFPR.

Rocha, F. S. M. (2018). Análise de projetos do Scratch desenvolvidos em um curso de formação de professores [Dissertação de Mestrado em Educação em Ciências e em Matemática, Universidade Federal do Paraná]. https://acervodigital.ufpr.br/handle/1884/59437

Silva, J. A. B. (2018). O Objeto de Aprendizagem - O skate e a Trigonometria. [Produto Educacional de Mestrado em Formação Científica, Educacional e Tecnológica, Universidade Tecnológica Federal do Paraná]. http://repositorio.utfpr.edu.br/jspui/handle/1/3892

Silva, J. A. B. (2018). Objetos de aprendizagem aplicados ao ensino da trigonometria: revelando elementos a partir do movimento histórico e lógico. [Dissertação de Mestrado em Formação Científica, Educacional e Tecnológica, Universidade Tecnológica Federal do Paraná]. http://repositorio.utfpr.edu.br/jspui/handle/1/3892 
Autores:

Taniele Loss. Doutoranda no Programa de Pós-Graduação em Formação Científica, Educacional e Tecnológica (PPGFCET) da Universidade Tecnológica Federal do Paraná (UTFPR); Mestre em Ensino de Ciências e Matemática pela UTFPR (2018); especialista em Metodologia do Ensino de Matemática pela Faculdade de Administração, Ciências, Educação e Letras (2011). Formada em Pedagogia pelo Centro Universitário Internacional Uninter (2020) e em Licenciatura em Matemática pelo Centro Federal de Educação Tecnológica do Paraná (CEFETPR, 2002). É membro do Grupo de Pesquisa sobre Inovações e Tecnologias na Educação (GPINTEDUC) e do Grupo de Pesquisa em Tecnologias na Educação Matemática (GPTEM). Tem experiência na Educação Básica e no Ensino Superior na modalidade presencial, mista e EAD. Atualmente é professora de Matemática do Ensino Fundamental II pela Secretaria Municipal da Educação de Curitiba.

Luciane Ferreira Mocrosky. Possui graduação em Licenciatura em Matemática pela Universidade Estadual de Ponta Grossa (1989), Mestrado em Educação Matemática pela Universidade Estadual Paulista Júlio de Mesquita Filho (UNESP/Rio Claro, 1997) e Doutorado em Educação Matemática pela Universidade Estadual Paulista Júlio de Mesquita Filho (UNESP/Rio Claro, 2010). Atualmente é professora Titular da Carreira EBTT na Universidade Tecnológica Federal do Paraná, no Programa de Pós-Graduação em Formação Científica, Educacional e Tecnológica (PPGFCET/UTFPR). Tem experiência na área de Educação com ênfase em Educação Matemática, atuando principalmente nos seguintes temas:

Educação Matemática, Ensino e Aprendizagem da Matemática, Formação de Professores e Educação Profissional. É membro dos seguintes Grupos de Pesquisa: Fenomenologia em Educação Matemática (FEM), Grupo de Estudos e Pesquisa em Formação de Professores (GEForProf) e Grupo de Pesquisa sobre Tecnologias na Educação Matemática e do Grupo de Estudos (GPTEM).

Fabiana Roberta Gonçalves e Silva Hussein. Possui graduação em Bacharelado em Química pela Universidade Federal de Pernambuco - UFPE (1992), Mestrado (1995) e Doutorado em Química (1999) pela UFPE. Fez o Pós-doutorado, com Bolsa do CNPq, no Institut de Chimie Minérale et Analytique da Université de Lausanne na Suíça (2000). Fez Pós-doutorado, com bolsa PNPD-Capes, na área de Educação Científica e Tecnológica no Programa de PósGraduação em Educação Científica e Tecnológica - PPGECT, na Universidade Federal de Santa Catarina (2018). Foi professora adjunto na Universidade Federal do Rio Grande do Norte e na Universidade Tecnológica Federal do Paraná - UTFPR, atuando na área de Ensino de Química e Química Geral. Atualmente é professora Titular da carreira Magistério Superior na Universidade Federal da Bahia, no Programa de Pós-Graduação em Formação Científica, Educacional e Tecnológica - UTFPR e no Programa de Pós-Graduação em Ensino, Filosofia e História das Ciências - UFBA. Orienta e orientou alunos de mestrado e doutorado na área de

Ensino de Química/Ciências. Suas atividades de pesquisa estão inseridas em: Formação de Professores de Química/Ciências; Ensino e aprendizagem; Abordagem Ciência, Tecnologia e Sociedade - CTS; Educação Inclusiva; Educação de Jovens e Adultos, Epistemologia e Atividades Lúdicas. 
Marcelo Souza Motta. Doutor em Ensino de Ciências e Matemática pela Universidade Cruzeiro do Sul (UNICSUL), mestre em Ensino de Ciências e Matemática pela Pontifícia Universidade Católica de Minas Gerais (PUCMG) e Graduação em Matemática pela Universidade Federal do Espírito Santo (UFES). Professor adjunto da Universidade Tecnológica Federal do Paraná (UTFPR). Coordenador da Especialização em Inovação e Tecnologias na Educação (INTEDUC). Professor permanente do Programa de Pós-Graduação em Formação Científica, Educacional e Tecnológica (PPGFCET) da UTFPR. Líder do Grupo de Pesquisa em Inovação e Tecnologias na Educação (GPINTEDUC). 